\title{
Outcomes of Single-Incision Laparoscopic Appendectomy at a Single Center*
}

\author{
Takahiro Watanabe", Hidetosi Wada, Masanori Sato, Yuichirou Miyaki, Junpei Tochikubo, \\ Norihiko Shiiya \\ Division of General Surgery and Endoscopic Surgery, Surgery I, Hamamatsu University School of Medicine, Hamamatsu, Japan \\ Email: " watanabetop78@yahoo.co.jp
}

Received August 1, 2013; revised September 1, 2013; accepted September 9, 2013

Copyright (C) 2013 Takahiro Watanabe et al. This is an open access article distributed under the Creative Commons Attribution License, which permits unrestricted use, distribution, and reproduction in any medium, provided the original work is properly cited.

\begin{abstract}
Background and Objectives: Recently, single-incision laparoscopic surgery has been popular for minimally invasive surgery and cosmetic improvement. We studied outcomes of single-incision laparoscopic appendectomy (SILA) in accordance with our strategy for acute appendicitis. Methods: Clinical outcomes were revealed in each of nine emergency SILA (e-SILA) cases and eight interval SILA (i-SILA) cases performed for the treatment of acute appendicitis between September 2010 and August 2012 at our hospital. Results: The male to female ratio was 6:3 for e-SILA and 5:3 for i-SILA cases. Mean ages were $33.1 \pm 17.8$ years and $41 \pm 21.6$ years for e-SILA and i-SILA, respectively. The pretreatment white blood cell (WBC) count and C-reactive protein (CRP) levels were $14960 \pm 4080 / \mu \mathrm{L}$ and $1.4 \pm 2.3 \mathrm{mg} / \mathrm{d}$, respectively, for e-SILA and $12657 \pm 4290 / \mu \mathrm{L}$ and $6.7 \pm 8.3 \mathrm{mg} / \mathrm{d}$, respectively, for i-SILA. The maximum transverse diameter of appendix was $12.6 \pm 3.5 \mathrm{~mm}$ for e-SILA and $11.6 \pm 3.5 \mathrm{~mm}$ for i-SILA. Appendiceal abscesses were encountered in one (11\%) e-SILA and three (38\%) i-SILA cases. Perforation of the appendix at operation occurred in two (22\%) e-SILA cases and no i-SILA cases. Generalized peritonitis occurred in $4(44 \%)$ e-SILA cases but in none of the i-SILA cases. The postoperative hospital stay was 5.3 days for e-SILA, 2.7 days for i-SILA. Conversion to laparotomy was not required in either group. One additional trocar was needed for an e-SILA case, and paralytic ileus occurred as a postoperative complication in one e-SILA case. Conclusion: The outcomes of SILA performed under our strategy were acceptable and useful without major postoperative complications.
\end{abstract}

Keywords: Laparoscopic Appendectomy; Single Access Laparoscopic Surgery; Minimally Invasive Surgery

\section{Introduction}

Since the initial report by Semm on laparoscopic appendectomy in 1983 [1], the procedure has been widely performed worldwide. Recently, single-incision laparoscopic appendectomy (SILA) has been increasingly performed in many surgical centers. In Japan, the cases of single-incision laparoscopic surgery have been increasing since 2000; we have employed SILA for the treatment of acute appendicitis since September 2010 in our hospital. In this study, we aimed to reveal outcomes of SILA in accordance with our strategy for acute appendicitis.

\section{Materials and Methods}

From September 2010 to August 2012, we performed 17 SILA procedures at Hamamatsu University School of Medicine. These included nine emergency SILA (e-SILA)

*Disclosure of interest: We report no conflict of interest.

\#Corresponding author. and eight interval SILA (i-SILA) cases. We revealed the clinical outcomes each of e-SILA and i-SILA.

Our treatment strategy for acute appendicitis is depicted in Figure 1. We performed e-SILA in cases of generalized peritonitis and those with likely perforated appendicitis such as a markedly swollen appendix, thinning of the appendix wall and impacted appendiceal calculi. Andi-SILA was adopted to avoid extended operations, such as ileocecal resections, and to decrease post-

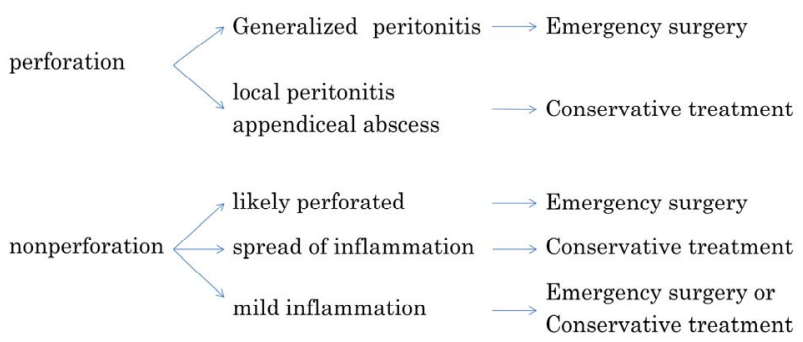

Figure 1. Our strategy of treatment for acute appendicitis. 
operative complications. We followed a conservative treatment for cases of local peritonitis, appendiceal abscesses, and spread of inflammation around the appendix. In cases requiring an interval appendectomy in order to avoid recurrent appendicitis following conservative therapy, i-SILA was performed a few months later. Patients selected e-SILA or i-SILA if they had mild inflammatory appendicitis along with the absence of aforementioned signs or symptoms.

Operation was performed using a $1.5-2.0 \mathrm{~cm}$ transumbilical vertical incision. Thereafter, the fascia and the peritoneum were opened vertically, and three 5 - $\mathrm{mm}$ trocars were inserted into the abdomen for introduction of endoscopic instruments. Carbon dioxide was used to inflate the abdomen at $8-10 \mathrm{mmHg}$ pressure. The operator used two $5-\mathrm{mm}$ forceps, and the first assistant manned a $30^{\circ} 5$-mm laparoscope (KarlStorz, Tuttlingen, Germany). The mesoappendix and appendicular vessel was dissected using laparoscopic coagulating shears. Once the cecum was mobilized to the umbilicus, the appendix was excised and removed via the transumbilical incision in all cases. A first or second generation cephalosporin antibiotic was administered only on the day of surgery in most cases ofi-SILA cases. Conversely, antibiotics such as second generation cephalosporin, tazobactam sodium/ piperacillin sodium and carbapenem were administered for an average of 4.4 days in e-SILA cases at the surgeon's discretion.

\section{Results}

The male to female ratio was $6: 3$ for e-SILA and 5:3 for i-SILA cases. Mean ages were $33.1 \pm 17.8$ years and $41 \pm$ 21.6 years for e-SILA and i-SILA, respectively. In addition, the pretreatment white blood cell (WBC) count and C-reactive protein (CRP) levels were $14960 \pm 4080 / \mu \mathrm{L}$ and $1.4 \pm 2.3 \mathrm{mg} / \mathrm{d}$, respectively, for e-SILA and $12657 \pm$ $4290 / \mu \mathrm{L}$ and $6.7 \pm 8.3 \mathrm{mg} / \mathrm{d}$, respectively, for i-SILA. Moreover, the maximum transverse diameter of appendix as measured by computed tomography was $12.6 \pm 3.5$ $\mathrm{mm}$ for e-SILA and $11.6 \pm 3.5 \mathrm{~mm}$ for i-SILA. Appendiceal abscesses were encountered in one (11\%) e-SILA and three (38\%) i-SILA cases. Perforation of the appendix at operation occurred in two (22\%) e-SILA cases and no i-SILA cases. Generalized peritonitis occurred in 4 (44\%) e-SILA cases but none of the i-SILA cases. The number of cases with appendiceal calculi totaled 7 (78\%) for e-SILA and 2 (25\%) for i-SILA (Table 1).

One additional trocar was used in a case of e-SILA with severe inflammation; however, no additional trocars were required in any of the i-SILA cases, and none of the cases in either group were converted to laparotomy. The operation times were $97 \pm 38 \mathrm{~min}$ for e-SILA and $78 \pm$ $32 \mathrm{~min}$ for i-SILA. Average blood loss was $5 \pm 8 \mathrm{ml}$ for e-SILA and $2 \pm 4 \mathrm{ml}$ for i-SILA. The postoperative com- plication of paralytic ileus developed in only one e-SILA case, and the patient recovered with conservative management. No other postoperative complications, including wound infections, were encountered. The postoperative length of hospital stay was $2.7 \pm 1.0$ days (range, 2 5 days) for patients undergoing i-SILA and $5.3 \pm 3.1$ days (range, 2 - 12 days) for patients undergoing e-SILA (Table 2).

\section{Discussion}

Since the first laparoscopic appendectomy was reported, the procedure has been extensively performed worldwide. Compared with open appendectomy, laparoscopic appendectomy has the benefits of a small incision size, less postoperative pain, decreased postoperative complications, shorter hospital stay, and improved cosmesis [2-4]. In Japan, single-incision laparoscopic surgery was reported for the first time in 2000 , and the number of cases undergoing this procedure has continued to increase since

Table 1. Characteristics of patients.

\begin{tabular}{ccc}
\hline & e-SILA & i-SILA \\
\hline Number of case & 9 & 8 \\
Male:Female & $6: 3$ & $5: 3$ \\
Age (years) & $33.1 \pm 17.8$ & $41 \pm 21.6$ \\
Original WBC $(/ \mu \mathrm{L})$ & $14960 \pm 4080$ & $12657 \pm 4290$ \\
Original CRP $(\mathrm{mg} / \mathrm{d})$ & $1.4 \pm 2.3$ & $6.7 \pm 8.3$ \\
Size of the appendix ${ }^{*}(\mathrm{~mm})$ & $12.6 \pm 3.5$ & $11.6 \pm 3.5$ \\
Appendiceal calculi ${ }^{* *}$ & $7(78 \%)$ & $2(25 \%)$ \\
Appendiceal abscess & $1(11 \%)$ & $3(38 \%)$ \\
Perforation of the appendix & $2(22 \%)$ & 0 \\
Generalized peritonitis & $4(44 \%)$ & 0 \\
\hline
\end{tabular}

WBC: White blood cell; CRP: C-reactive protein; SILA: single-incision laparoscopic appendectomy; e-: emergency; i-: interval; "Measuring the diameter of the appendix on the CT examination; ${ }^{* *}$ Appendiceal calculi that can be identified on the CT examination.

Table 2. Outcomes of e-SILA and i-SILA.

\begin{tabular}{ccc}
\hline & e-SILA & i-SILA \\
\hline Additional ports & $1(11 \%)$ & 0 \\
Conversion to laparotomy & 0 & 0 \\
Operation time (min) & $97 \pm 38$ & $78 \pm 3$ \\
Blood loss (ml) & $5 \pm 8$ & $2 \pm 4$ \\
Postoperative complication & 1 (paralytic ileus) & 0 \\
Postoperative length of stay & $5.3 \pm 3.1$ & $2.7 \pm 1.0$ \\
\hline
\end{tabular}

SILA: single-incision laparoscopic appendectomy. 
2008. The purpose of this research was to reveal outcomes of SILA in accordance with the specific strategy used at our hospital. Then, our result was acceptable without major postoperative complications.

There are differences in strategies for acute appendicitis in each hospital. Surgical site infection (SSI) is the most common complication after appendectomy. Margenthaler et al. [5] reported the incidence of SSI after appendectomy to be approximately $8 \%$. It is essential to reduce the incidence of SSI for improving the outcome following appendicitis. In previous reports [6-8], a wound infection rate of about $5 \%$ for single-incision appendectomies has been described, which was higher than conventional laparoscopic appendectomy. In our study, however, wound infection was not encountered. Appropriate surgical practices such as gentle manipulation and adequate wound protection are essential to prevent SSI. Our operation time for SILA was longer than that reported in previous studies $[9,10]$. One reason for this discrepancy may be our surgical technique. We performed extracorporeal appendectomies through a single umbilical incision after the cecum was mobilized to the umbilicus, if necessary. The merit of this method is that when appendiceal calculi are impacted at the appendiceal base, we can easily manage this situation under direct vision. However, Kang et al. [10] reported the importance of selecting intra- or extracorporeal appendectomy whether the cecum is mobile or not in order to avoid unnecessary manipulation and reduce operation time.

A total of 20 cases underwent conservative treatment for acute appendicitis at our hospital from September 2010 to August 2012. Two cases (10\%) were converted to e-SILA because of severe inflammation, 8 cases $(40 \%)$ underwent i-SILA, and 10 cases $(50 \%)$ did not undergo any operation. At the discretion of the attending physician, antibiotics such as second generation cephalosporin, tazobactam sodium/piperacillin sodium, and carbapenem were administered for an average of 5.4 days as our conservative treatment. The hospital stay during conservative treatment averaged 7.3 days (range, $4-20$ ), and the outcomes were acceptable. As i-SILA was performed after the inflammation subsided, under our treatment regimen, patients in this group were able to be discharged considerably earlier compared with those in the e-SILA group.

\section{Conclusion}

In conclusion, the outcomes of SILA performed under our strategy were acceptable and useful without major postoperative complications.

\section{REFERENCES}

[1] K. Semm, "Endoscopic Appendectomy," Endoscopy, Vol. 15, No. 2, 1983, pp. 59-64. http://dx.doi.org/10.1055/s-2007-1021466

[2] S. Towfigh, F. Chen, R. Mason, N. Katkhouda, L. Chan and T. Berne, "Laparoscopic Appendectomy Significantly Reduces Length of Stay for Perforated Appendicitis," Surgical Endoscopy and Other Interventional Techniques, Vol. 20, No. 3, 2006, pp. 495-499. http://dx.doi.org/10.1007/s00464-005-0249-8

[3] M. N. Khan, T. Fayyad, T. D. Cecil and B. J. Moran, "Laparoscopic versus Open Appendectomy: The Risk of Postoperative Infectious Complications," Journal of the Society of Laparoendscopic Surgeons, Vol. 11, No. 3, 2007, pp. 363-367.

[4] R. Golub, F. Siddiqui and D. Pohl, "Laparoscopic versus Open Appendectomy: A Metaanalysis," Journal of the American College of Surgeons, Vol. 186, No. 5, 1998, pp. 545-553. http://dx.doi.org/10.1016/S1072-7515(98)00080-5

[5] J. A. Margenthaler, W. E. Longo, K. S. Virgo, et al., "Risk Factors for Adverse Outcomes after the Surgical Treatment of Appendicitis in Adults," Annals of Surgery, Vol. 238, No. 1, 2003, pp. 59-66. http://dx.doi.org/10.1097/01.SLA.0000074961.50020.f8

[6] A. A. Saber, M. H. Elgamal, T. H. El-Ghazaly, A. V. Dewoolkar and A. Akl, "Simple Technique for Single Incision Transumbilical Laparoscopic Appendectomy," International Journal of Surgery, Vol. 8, No. 2, 2010, pp. 128-130. http://dx.doi.org/10.1016/j.ijsu.2009.12.001

[7] J. Lee, J. Baek and W. Kim, "Laparoscopic Transumbilical Single-Port Appendectomy: Initial Experience and Comparison with Three-Port Appendectomy," Surgical Laparoscopy, Endoscopy \& Percutaneous Techniques, Vol. 20, No. 2, 2010, pp. 100-103. http://dx.doi.org/10.1097/SLE.0b013e3181d84922

[8] H. J. Kim, J. I. Lee, Y. S. Lee, et al., "Single-Port Transumbilical Laparoscopic Appendectomy: 43 Consecutive Cases," Surgical Endoscopy, Vol. 24, No. 11, 2010, pp. 2765-2769. http://dx.doi.org/10.1007/s00464-010-1043-9

[9] J. A. Lee, K. Y. Sung, J. H. Lee and D. S. Lee, "Laparoscopic Appendectomy with a Single Incision in a Single Institute," Journal of the Korean Society of Coloproctology, Vol. 26, No. 4, 2010, pp. 260-264. http://dx.doi.org/10.3393/jksc.2010.26.4.260

[10] D. B. Kang, S. H. Lee, S. Y. Lee, et al., "Application of Single Incision Laparoscopic Surgery for Appendectomy in Children," Journal of the Korean Surgical Society, Vol. 82, No. 2, 2012, pp. 110-115.

http://dx.doi.org/10.4174/jkss.2012.82.2.110 